2. National Library of Medicine. Charting a course for the 21st century: NLM's long range plan 2006-2016 [Internet]. Bethesda, MD: The Library, National Institutes of Health; Sep 2006 [cited 11 Dec 2015]. < https://www.nlm.nih.gov/ pubs/plan/lrp06/report/LRP_Goal4.html $>$.

3. National Library of Medicine. K-12 science and health education [Internet]. Division of Specialized Information Services, The Library [cited 11 Dec 2015]. <https://sis. nlm.nih.gov/outreach/k12.html>.

\section{AUTHOR'S AFFILIATION}

Yamila M. El-Khayat, MA, yme@ahsl.arizona.edu, Outreach Services Librarian, Arizona Health Sciences Library, University of Arizona, Tucson, AZ

Received July 2015; accepted February 2016

\title{
Virtual embedded librarianship program: a personal view ${ }^{\star} E C$
}

\section{Trey Lemley, MLIS, JD, AHIP}

See end of article for author's affiliation.
This commentary provides an overview of the author's experience as a virtual embedded librarian with the University of South Alabama College of Nursing. My involvement has increased every semester, and most recently, I have been assigned as the solo librarian to classes with 300-500 students. As a virtual embedded librarian, I have never interacted with an enrolled master of science in nursing (MSN)/doctor of nursing practice (DNP) student face to face; however, I have spoken live via telephone with students throughout the United States and abroad, including from Canada, Germany, and Japan. Herein, I present a brief overview of the embedded concept. In addition to summarizing my responsibilities, I discuss the challenges that I have faced and best practices for developing an embedded librarianship program.

\section{A NEW MODEL OF LIBRARIANSHIP}

Technology has changed the way people use information, and as a consequence, traditional models of reference are not always the most effective means of providing service to library users. In an effort to increase responsiveness and relevance, the embedded librarian model has developed as a new paradigm of librarianship to take "library services and resources to the user, regardless of the user's

\footnotetext{
* Based on a poster presentation at MLA'15, the 115 Annual Meeting of the Medical Library Association; Austin, TX; May 17, 2015.

Supplemental Figure1 and Figure 2 are available with the online version of this journal.
}

locale, through various effective routes that will meet the needs of the users" [1]. In contrast to the traditional model of reference in which the librarian serves one library user at a time, the embedded librarian becomes a team member by providing personalized services through integration, collaboration, and establishment of a strong working relationship with an entire community of information users [2].

Another distinguishing characteristic of the embedded model is its proactive focus: instead of simply responding, the embedded librarian anticipates information needs and provides customized "bespoke" service to the user group.

\section{A NEW MODEL OF EDUCATION}

The MSN and DNP programs of the University of South Alabama College of Nursing are offered exclusively in an online and asynchronous format; therefore, students do not come to the physical campus to attend classes. Because students (and some faculty) are located throughout the United States and in foreign countries, it would be impossible for a librarian to provide traditional "inperson" reference service. Therefore, nursing faculty and librarians decided to "embed" librarians of the University of South Alabama Biomedical Library in online nursing courses. In 2012, I became a virtual embedded librarian in graduate nursing courses, after a long period of scholarly collaboration with University of South Alabama nursing faculty, which 
included the coauthorship of journal articles and a chapter in a nursing textbook.

\section{DESCRIPTION OF ACTIVITIES}

As an embedded librarian, I am officially enrolled in courses and am listed as an "instructor" on the roster in USAOnline, the educational software platform and course management system by which the University of South Alabama offers online courses. In USAOnline, each course (and course section) has its own course page, arranged by tab on the left-hand sidebar for easy navigation (Figure 1, online only).

As an instructor, I have access to all course information and sections of the course page, including the Assignments, Lessons, Roster, and Gradebook tabs. In addition, I can prepare content for inclusion in the Lessons or Resources sections by the nursing faculty. I can personally post content, such as a tutorial, to several sections of the course page, including the Announcements section (Figure 1, online only) and the Forums section, which contains several threaded discussion boards including the Reference Desk, a section of the course page designed to be a virtual reference desk (Figure 2, online only).

On a daily basis, I check my email, voicemail, and the Reference Desk discussion board for questions from students. I prepare tutorials and videos on a wide variety of topics such as finding information for the next assignment, obtaining articles via interlibrary loan, and searching the literature for nurse-authored articles. I provide information on relevant library resources and the search capabilities of different databases.

With regard to faculty, I regularly contact nursing professors to discuss course assignments, to remind them of my availability for help, and to make suggestions for course-related resources of possible value to students. Further, I try to keep my colleagues in the library's reference department "in the loop" by informing them of upcoming course assignments and requirements, in the event that students contact the reference desk instead of me. In addition, I forward to my coworkers any tutorials I prepare for the class.

Since the courses for which I am embedded are core graduate-level classes with heavy research demands, many questions from students involve searching the scientific literature for information on paradigms for performing scholarly research. Although course assignments vary each semester, they generally require students to find an appropriate meta-analysis, a meta-synthesis, a systematic review, or evidence-based guideline on a particular topic. Students request instruction on how to locate these study types in the scientific literature, and many students will ask basic questions such as the definition of a systematic review, meta-analysis, or meta-synthesis. Citation questions involving American Psychological Association (APA) formatting and style are also popular. Other commonly asked questions include:

- How do I navigate the library's home page?

- What are the best databases to search for my topic?

- How do I search CINAHL?

- How do I request an article via interlibrary loan?

\section{CHALLENGES}

The time commitment has become more substantial as my involvement has increased. Because I am the only embedded librarian in a class with high enrollments, I can be inundated with questions when an assignment deadline draws near. (Recently, I was assigned to 1 class with 27 sections and about 20 students in each section, for a total of over 500 students for the semester alone.)

Although the Reference Desk section of the course page in USAOnline is a discussion board, intended to be a forum where students can ask questions of the embedded librarian, students sometimes post nonlibrary-related messages to their nursing instructor or other class members in this section. In addition, occasionally a student responds with inaccurate information to questions by classmates that are intended for the librarian.

There is a significant issue with role confusion: some students confuse my role as a librarian with that of the primary instructor, who is a member of the nursing faculty. Because I am listed in the course roster as an instructor, I often receive questions from students that should be addressed to the nursing faculty member, such as requests for time extensions for assignments or questions about grades received, matters over which I have no control. Other students want me to "vet" their assignments for them before submission for a grade (for instance, "Is this study a meta-synthesis?").

While most students are self-sufficient, there are those who want extra attention because they have been out of school for a long time, they are rusty in their study skills, or they need help mastering the actual course content. I help students in any way I 
can; however, I do not want to usurp the role of the professor, and in these situations, I refer students to their primary instructors, in accordance with the directives of the nursing faculty.

Because it is not possible to simultaneously add the same written information (for instance, a tutorial) to the course pages of all sections of a class in the USAOnline course management system, I have to enter the same information into each section individually: to illustrate, if I am embedded in twenty-seven sections of a class, I must access each section's course page to enter the announcement, for a total of twenty-seven times. This is time consuming.

Finally, it can be challenging to assess my effectiveness.

\section{BEST PRACTICES}

Shumaker lists the following best practices for the embedded librarian [3].

- Be an advocate, be adaptable, be proactive.

- Maintain a strong presence with user groups.

- Go where the action is: bring library resources and services to the attention of the user group.

- Attend departmental events, meetings, or planning sessions.

- Publish and present with subject faculty.

From my personal experience as a virtual embedded librarian, I have tried to build and nurture strong relationships with user groups by

understanding and anticipating their needs. In turn, faculty buy-in is vital: faculty must be convinced that the embedded librarian can add value, and to this end, librarians must "prove their worth." In turn, once the faculty is "on board," it becomes easier to obtain the students' support.

But the relationship, once established, cannot remain static: the embedded role is an ongoing partnership, and contact with all groups must be cultivated. As an example, posting online tutorials and announcements is an excellent way to stay on your users' radar, in the process creating a strong "embedded" culture and presence. In addition, I contact faculty on a regular basis to keep the lines of communication open and to offer my services as a colleague and partner. This is especially important when there is significant faculty rotation from semester to semester, because I want to ensure that new faculty knows who I am and what I do. As an illustration, in an effort to make sure we were "on the same page," I have contacted faculty to obtain examples both of student papers and research studies on a particular topic that in the professor's opinion were exemplary. Furthermore, I encourage students to contact me by phone, email, or via the Reference Desk discussion board in USAOnline.

\section{CONCLUSION}

The embedded librarian model is an exciting new development in the field of librarianship that should prove even more important as online educational programs proliferate, offering tremendous growth potential for the services of librarians. The embedded model allows librarians to engage users where they are. To succeed, embedded librarians must understand and anticipate user needs and should devote significant amounts of time and resources to establish and nurture relationships with faculty and students, developing a strong presence in the process, which is harder to do in the online environment.

\section{REFERENCES}

1. Konieczny A. Experiences as an embedded librarian in online courses. Med Ref Serv Q. 2010 Jan;29(1):47-57. DOI: http://dx.doi.org/10.1080/02763860903485084.

2. Wu L, Mi M. Sustaining librarian vitality: embedded librarianship model for health sciences libraries. Med Ref Serv Q. 2013 Aug;32(3):257-65. DOI: http://dx.doi.org/10. 1080/02763869.2013.806860.

3. Shumaker D. The embedded librarian. Medford, NJ: Information Today, 2012.

\section{AUTHOR'S AFFILIATION}

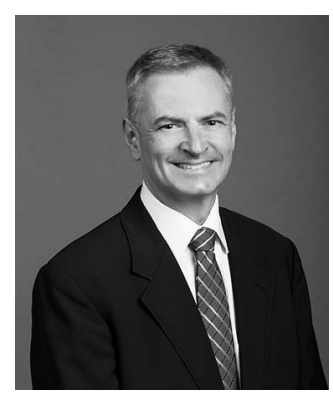

Trey Lemley, MLIS, JD, AHIP, Lemley@southalabama. edu, Information Services Librarian/Scholarly Communications Librarian, Biomedical Library, University of South Alabama, 5791 USA Drive North, CBBL 214, Mobile, AL 36688

Received December 2015; accepted February 2016 